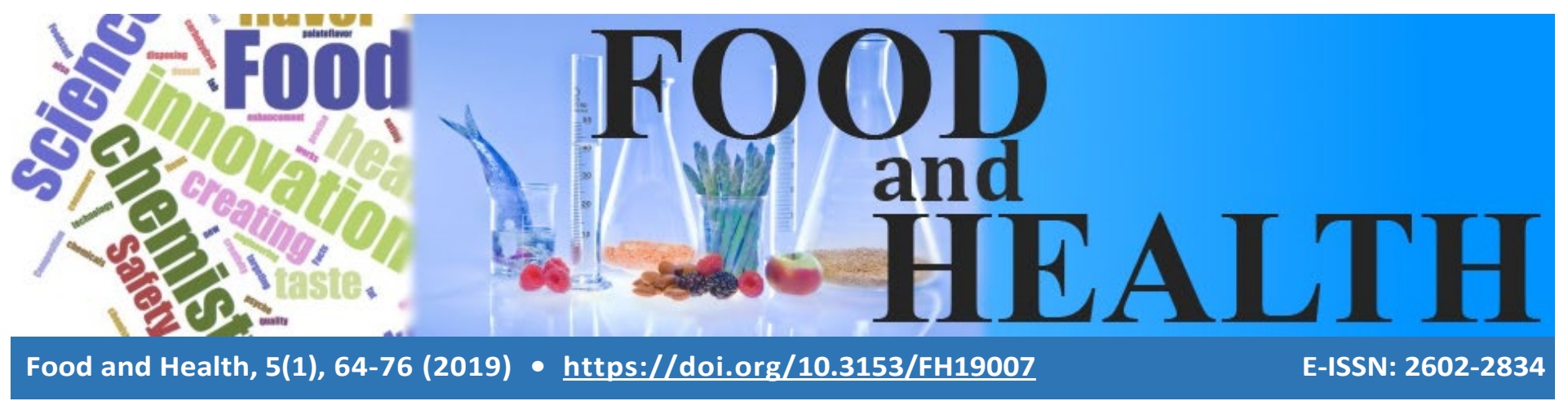

Research Article

\title{
TRANSGALACTOSYLATION FOR GALACTOOLIGOSACCHARIDE SYNTHESIS USING PURIFIED AND CHARACTERIZED RECOMBINANT a-GALACTOSIDASE FROM Aspergillus fumigatus IMI 385708 OVEREXPRESSED IN Aspergillus sojae
}

\author{
Sümeyra Gürköki ${ }^{(D)}$, Zümrüt B. Ögel \\ Cite this article as: \\ Gürkök, S., Ögel, Z.B. (2019). Transgalactosylation for galactooligosaccharide synthesis using purified and characterized recombinant alpha-galacto- \\ sidase from Aspergillus fumigatus IMI 385708 overexpressed in Aspergillus sojae. Food and Health, 5(1), 64-76. https://doi.org/10.3153/FH19007
}

\footnotetext{
1 Ataturk University, Faculty of Science, Department of Biology, 25240 Erzurum Turkey

2 Konya Food and Agriculture University, Faculty of Engineering and Architecture, Department of Food Engineering, 42080 Konya Turkey
}

Submitted: 15.03 .2018

Accepted: 26.07.2018

Published online: 25.10 .2018

Correspondence:

Sümeyra GÜRKÖK

E-mail: sumeyrag@gmail.com

๑ Copyright 2019 by ScientificWebJournals

Available online at http://jifhs.scientificwebjournals.com

\begin{abstract}
Galactooligosaccharides are well-known functional food ingredients with prebiotic properties. Recent trend for the use of galactooligosaccharides in the food industry leads the search for new enzymes for their production. $\alpha$-Galactosidase from Aspergillus fumigatus IMI 385708, possessing a highly efficient debranching ability on polymeric substrates, is also able to perform transgalactosylation. In this study, recombinant $\alpha$-galactosidase produced by Aspergillus sojae Ta1 was purified 18.7-fold using anion exchange and hydrophobic interaction chromatography with an overall yield of $56 \%$ and $64.7 \mathrm{U} / \mathrm{mg}$ protein specific activity. The $\mathrm{V}_{\max }$ and $\mathrm{K}_{\mathrm{m}}$ values for the hydrolysis of $p \mathrm{NP}-$ Gal were $78 \mathrm{U} / \mathrm{mg}$ protein and $0.45 \mathrm{mM}$, respectively. Optimum $\mathrm{pH}(\mathrm{pH} 4.5)$ and temperatures (50$60^{\circ} \mathrm{C}$ ) for recombinant $\alpha$-galactosidase activity were determined. For the synthesis of oligosaccharides, purified and characterized recombinant $\alpha$-galactosidase was used in the transgalactosylation of various mono- and disaccharides using $p$ NPGal ( $p$-nitrophenyl- $\alpha-D$-galactopyranoside) as galactose donor. Di- and trisaccharides obtained by transgalactosylation were analysed by TLC, ESI-MS, and HPLC analysis. Among 12 acceptor candidates, $\alpha$-galactosidase transgalactosylated galactose, glucose, mannose, cellobiose, lactose, maltose, and sucrose efficiently, however, did not transgalactosylate xylose, arabinose, fucose, fructose, and melibiose.
\end{abstract}

Keywords: $\alpha$-Galactosidase, Aspergillus, Characterization, Transgalactosylation, Galactooligosaccharides, Prebiotics 


\section{Introduction}

$\alpha$-Galactosidase (EC 3.2.1.22; alpha- $D$-galactoside galactohydrolase) is an exo-glycosidase that catalyses the hydrolysis of terminal, non-reducing $\alpha$-1,6-linked-D-galactose residues from simple galactose-containing oligosaccharides such as melibiose, raffinose, and stachyose in addition to the more complex polysaccharides including galactomannans and galactoglucomannans (Dey and Pridham, 1972). The enzyme has many biotechnological, medical, and industrial applications with its hydrolytic activity (Dey et al., 1993; Katrolia et al., 2014). Currently, glycosyl hydrolases have gained interest with their transgalactosylation activities for research and industrial applications (Wang et al., 2014).

Galactooligosaccharides (GOS), which are not digested by human gastrointestinal tract due to the lack of $\alpha$-galactosidase enzyme, are one of the most important oligosaccharides, which fulfil the criteria for prebiotics. These undigested oligosaccharides are selectively fermented by gastrointestinal microbiota and beneficially affect the human health by promoting the growth of the beneficial bacteria like Bifidobacterium and Lactobacilli (Gibson and Roberfroid, 1995). Although there are some GOS prebiotics on the market currently, there is still great interest in the reliable production and improvement of new prebiotic and novel glycan-based drugs candidates.

The synthesis of GOS via enzymatic ways has advantages over the chemical approaches, which are usually laborious and expensive due to the protection and de-protection steps. Glycosyl transferases and glycosidases are employed to glycosylate carbohydrate substrates. Glycosyl transferases catalyse the transfer of the glycosyl residue to the acceptor efficiently and selectively, however, they require for a complex glycosyl donor and glycosyl transferases are not available as the glycosidases. In contrast, the glycosidases, which are readily available and inexpensive, use simpler glycosyl donors. Its main disadvantage is that regioselectivity may not be observed in all cases (Crout and Vic, 1998). Glycosidases are used for the synthesis of glycosides in two ways. In the thermodynamic procedure (reverse hydrolysis), the hydrolysis is reversed by the conversion of the equilibrium of the reaction from hydrolysis towards synthesis. In this approach, free monosaccharides are used as substrate without any activation. In the kinetic way (transglycosylation), activated glycosyl donors with poor nucleophilicity, which bears an aglycone moiety with good leaving groups are employed. The enzyme-glycoside intermediate is then attacked by a nucleophilic molecule other than water and a new glycoside is formed. As the yields of glycoside synthesis is higher, transglycosylation approach is preferred over the reverse hydrolysis (Kurt, 2011).

Some $\alpha$-galactosidases have the transgalactosylation activity that has been performed using either melibiose or pNP$\alpha-D$-galactopyranoside as the donor, resulting in the synthesis of various galactooligosaccharides (Hashimoto et al., 1995; Hinz et al., 2005; Van Laere et al., 1999). A. fumigatus $\alpha$-galactosidase was previously shown to catalyse unique transgalactosylation reaction to a variety of monosaccharides, disaccharides, and oligosaccharides including the maltooligosaccharides, cellooligosaccharides, and mannooligosaccharides (Puchart and Biely, 2005). However, the efficiency was very low with monosaccharide and disaccharide acceptors. A. fumigatus $\alpha$-galactosidase, having novel glycosylation activity by transferring the galactosyl units to internal sugar units of acceptor molecules, is worth to be studied in more detail for mono- and disaccharide transgalactosylation. As it is an opportunistic human pathogen, $A$. fumigatus is not suitable for such applications. Therefore, in our previous study, cloning, heterologous expression, and optimization of the heterologous production of $\alpha$-galactosidase from A. fumigatus were reported in A. sojae (Gurkok et al., 2010; Gurkok et al., 2011).

Here, together with the hydrolytic activity, the transgalactosylation activity of $A$. fumigatus $\alpha$-galactosidase was investigated after purification and characterization of the extracellular enzyme produced in $A$. sojae Ta1. Different monoand disaccharides were tested as acceptor in $\alpha$-galactosidase mediated transgalactosylation in the presence of pNPGal donor and the results were analysed by TLC, ESI-MS, and HPLC. Enzymatic formation of galactosyl-galactose, galactosyl-glucose, galactosyl-mannose, galactosyl-cellobiose, galactosyl-lactose, galactosyl-maltose, and galactosyl-sucrose was successfully achieved with $\alpha$-galactosidase from A. fumigatus $\alpha$-galactosidase.

\section{Materials and Methods}

\section{Strain, Media, and Cultivation}

Recombinant $A$. sojae ( $A$. sojae Ta1) expressing $\alpha$-galactosidase of $A$. fumigatus (IMI 385708) was cultivated on modified YpSs broth $\left(4 \mathrm{~g} / \mathrm{L}\right.$ yeast extract, $1 \mathrm{~g} / \mathrm{L} \mathrm{K}_{2} \mathrm{HPO}_{4}, 0.5 \mathrm{~g} / \mathrm{L}$ $\mathrm{MgSO}_{4} 7 \mathrm{H}_{2} \mathrm{O}$, and $20 \mathrm{~g} / \mathrm{L}$ glucose). The cultivations were carried out in $250 \mathrm{~mL}$ Erlenmeyer flasks with $100 \mathrm{~mL}$ working volume and incubated at $30^{\circ} \mathrm{C}$ in a shaker incubator at $155 \mathrm{rpm}$ for three days (Gurkok et al., 2010). 


\section{Purification of Recombinant $\alpha$-Galactosidase}

Purification of recombinant $\alpha$-galactosidase ( $r-\alpha$-galactosidase) was performed with the ÄKTA Prime FPLC system, (Amersham Biosciences, Sweden) according to a two-step purification technique including anion exchange and hydrophobic interaction chromatography. Supernatant was withdrawn from the third day of cultivation and was filtered through pre-weighed Whatman no. 1 filter paper to remove mycelia. Supernatant filtrate (crude extract) and all liquids used for purification were filtered through $0.45 \mu \mathrm{m}$-poresize membrane (Millipore, USA) before use.

Anion exchange chromatography (AEC) was performed in a $20 \mathrm{~mL}$ prepacked, ready to use HiPrep ${ }^{\mathrm{TM}}$ 16/10 Q XL Column (Amersham Biosciences, USA). The culture filtrate was applied to the column, previously equilibrated with 50 $\mathrm{mM}$ sodium phosphate buffer, $\mathrm{pH} 6.0$ (buffer A). $5 \mathrm{~mL}$ fractions were collected during elution at the flow rate 0.5 $\mathrm{mL} / \mathrm{min}$ with a salt gradient in the range of $0-0.5 \mathrm{M}$ sodium chloride, prepared in buffer A. All fractions were checked for $\alpha$-galactosidase activity by standard assay conditions.

$\alpha$-Galactosidase active fractions of AEC were pooled, and directly applied to hydrophobic interaction chromatography (HIC) conducted in a $53 \mathrm{~mL}$ prepacked, ready to use HiPrep $^{\text {TM }}$ 26/10 Desalting Column (Amersham Biosciences, USA). Column was previously equilibrated with $1.3 \mathrm{M}$ $\left(\mathrm{NH}_{4}\right)_{2} \mathrm{SO}_{4}$ in buffer A. Elution was done at the flow rate of $0.3 \mathrm{~mL} / \mathrm{min}$ and $3 \mathrm{~mL}$ fractions were collected. Adsorbed proteins were liberated from the carrier with linear decreasing gradient of 1.3-0 $\mathrm{M}\left(\mathrm{NH}_{4}\right)_{2} \mathrm{SO}_{4}$ in buffer $\mathrm{A}$. $\alpha$-Galactosidase active fractions were pooled and specific activities, yields, and degree of purification were calculated.

The concentration of total protein was measured by the Lowry Method (Lowry et al., 1951) with bovine serum albumin as standard protein.

Purity and molecular weights of the proteins were assessed by means of sodium dodecyl sulphate polyacrylamide gel electrophoresis (SDS-PAGE) performed according to the standard protocol of Laemmli (Laemmli, 1970) using Serva BlueFlash S, $15 \mathrm{~cm} \times 28 \mathrm{~cm} \times 8.5 \mathrm{~cm}$ electrophoresis system. Later the gels were stained with Coomassie Brillant Blue G-250. PageRuler ${ }^{\mathrm{TM}}$ Prestained Protein Ladder Plus (Fermentas Life Sciences, USA) was used as molecular weight standard.

\section{$\alpha$-Galactosidase Activity Assay}

$\alpha$-Galactosidase activity towards para-nitrophenyl- $\alpha$-D-galactopyranoside ( $p$ NPGal) was measured as described earlier (Gurkok et al., 2010). Specific activity of the enzyme was expressed in units of enzyme activity per milligram of protein. The data presented for all $\alpha$-galactosidase activity determinations were mean values of triplicate assays, in which the standard deviations always lay under $10 \%$.

\section{$N$-Deglycosylation of the Recombinant $\alpha$-Galactosidase}

$\mathrm{N}$-Deglycosylation was performed by the N-Glycanase enzyme (Peptide-N-Glycosidase F) (ProZyme, USA). $100 \mu \mathrm{g}$ of purified $\alpha$-galactosidase sample was prepared in $45 \mu \mathrm{L}$ of $1 \mathrm{X}$ reaction buffer. $2.5 \mu \mathrm{L}$ of SDS / $\beta$-mercaptoethanol (final reaction concentration $0.1 \%$ SDS, $50 \mathrm{mM} \beta$-mercaptoethanol) solution was added and the mixture was denatured by heating at $100^{\circ} \mathrm{C}$ for 5 minutes. After cooling, 2.5 $\mu \mathrm{L}$ Tergitol-type NP-40 (final concentration $0.75 \%$ NP-40) and $2.5 \mu \mathrm{L} \mathrm{N}$-Glycanase were added to the reaction mixture and incubated overnight at $37^{\circ} \mathrm{C}$. NetNGlyc 1.0 Server program was used for the prediction of $\mathrm{N}$-glycosylation sites (N-X-S/T) (Gupta et. al., 2004).

\section{Kinetic Analysis}

Kinetic studies were performed using $p$ NPGal substrate at concentrations ranging from 0.1 to $3.5 \mathrm{mM}$ prepared in 100 $\mathrm{mM}$ phosphate buffer ( $\mathrm{pH} 4.5$ ). Enzyme activity was measured under standard assay conditions and the kinetic constants $\mathrm{K}_{\mathrm{m}}$ and $\mathrm{V}_{\max }$ were determined from Lineweaver-Burk plot using the nonlinear regression analysis program of the GraphPad Prism $v 5$ trial version.

\section{Effect of pH, Temperature, and Chemical Reagents}

Optimum $\mathrm{pH}$ of $\alpha$-galactosidase was determined by performing activity assays at a $\mathrm{pH}$ range of 2.5-8.0 with buffers at concentration of $50 \mathrm{mM}$. The buffer systems used were sodium citrate for $\mathrm{pH}$ 2.5-3.0, sodium acetate for $\mathrm{pH} 4.0$ 4.5, and sodium phosphate for $\mathrm{pH}$ 4.0-8.0. Temperature, enzyme concentration, and substrate concentration were kept constant as stated in the standard assay condition. To determine $\mathrm{pH}$ stability, enzyme solutions were incubated at a $\mathrm{pH}$ range of 2.5-8.0 for $2 \mathrm{~h}$ and $4 \mathrm{~h}$. The residual activities were determined by the standard assay conditions and reported as the ratio of enzyme activity after $\mathrm{pH}$ treatment to the initial maximum activity at $\mathrm{pH} 4.5$.

Optimum temperature of $\alpha$-galactosidase was determined at a temperature range of 20 to $80^{\circ} \mathrm{C}$. Enzyme concentration, substrate concentration, and $\mathrm{pH}$ were kept constant as stated in standard assay condition. Temperature stability of $\alpha$-galactosidase was determined by measuring residual $\alpha$-galactosidase activity after the enzyme solution was pre-incubated at temperatures ranging from 20 to $80^{\circ} \mathrm{C}$ for 1,3 , and $5 \mathrm{~h}$. The residual activities were determined by the standard activity assay conditions and reported as the ratio of the enzyme activity after temperature treatment to the initial maximum activity at $50^{\circ} \mathrm{C}$. 
$\alpha$-Galactosidase was pre-incubated in the presence of $1 \mathrm{mM}$ of various metal ions and chemicals for $90 \mathrm{~min}$ at room temperature. After incubations, the residual activities were determined by the standard activity assay and reported as the ratio of the enzyme activity to the initial maximum activity obtained in the absence of these chemicals.

Error bars in the figures related to activity measurements represent the standard deviations from the mean of three independent experiments.

\section{Transgalactosylation Reaction}

L-Arabinose, L-fucose, D-fructose, D-xylose, D-galactose, D-glucose, D-mannose, cellobiose, lactose, maltose, melibiose, and sucrose were used as acceptors. The donor sugar was $p$ NPGal. As the donor sugar is more expensive than acceptor sugars, acceptor sugars were used in excess amounts to push the reaction towards synthesis instead of hydrolysis. Purified $\alpha$-galactosidase was used in all transgalactosylation experiments. $0.5 \mathrm{U} / \mathrm{mL}$ purified $\alpha$-galactosidase, $1 \mathrm{M}$ acceptor sugar and $0.25 \mathrm{M}$ donor sugar were mixed in $100 \mathrm{mM}$ sodium phosphate buffer, $\mathrm{pH} 4.5$ and incubated at $50^{\circ} \mathrm{C}$ for 1 hour and terminated by heating at $95^{\circ} \mathrm{C}$ for 5 minutes.

\section{Analysis of Transgalactosylation Products}

After enzyme inactivation, the transgalactosylation reaction mixtures were monitored by thin layer chromatography (TLC) on silica-coated aluminium sheets (Merck, Darmstadt, Germany). The heated mixtures were diluted 50-fold with $100 \mathrm{mM}$ sodium phosphate buffer, $\mathrm{pH} 4.5$ and $1 \mu \mathrm{L}$ diluted aliquot was loaded onto the TLC plate. $n$-Butanol:Ethanol:Water (10:8:7) solvent system was used as mobile phase. In order to visualize sugar spots, the TLC plates were dipped into the jar containing $0.2 \%(\mathrm{~m} / \mathrm{V})$ recorcin in $10 \%(\mathrm{~V} / \mathrm{V}) \mathrm{H}_{2} \mathrm{SO}_{4}$ in ethanol and dried 10 minutes at $100{ }^{\circ} \mathrm{C}$ (Puchart and Biely, 2005).

To confirm the transgalactosylation, $10 \mu 1$ of the diluted aliquot was completely dissolved in 50:50 solution of water: ACN containing $0.1 \%$ formic acid and analysed by electrospray ionization-time of flight mass specrometry (ESITOF MS). ESI-TOF MS was performed using Waters LCT (Waters Corporation, MA. USA). Samples were injected using a Waters Alliance auto-sampler in the mobile phase of 50:50 solution of water: ACN containing $0.1 \%$ formic acid at $0.1 \mathrm{~mL} /$ hour flow rate. MS detection was performed in positive mode keeping the capillary voltage at $3 \mathrm{kV}$ and capillary temperature of $200{ }^{\circ} \mathrm{C}$. The data was analysed with Waters OpenAccess and Masslynx software.

Quantitative analysis of transgalactosylation reaction was carried out by Varian Prostar HPLC system on Varian MetaCarb 87H Column ( $300 \mathrm{X} 7.8 \mathrm{~mm})$ coupled to ProStar 350 Refractive Index Detector. $0.008 \mathrm{~N} \mathrm{H}_{2} \mathrm{SO}_{4}$ was used as mobile phase. $50 \mu \mathrm{L}$ samples were injected and eluted at a flow rate of $0.5 \mathrm{~mL} / \mathrm{min}$ at $35^{\circ} \mathrm{C}$. Varian Star Workstation Software processed data obtained from HPLC. Quantitative analysis was carried out using calibration curves of the corresponding acceptor as the reference. The yield was calculated as the ratio of transgalactosylated acceptor amount to initial acceptor amount.

\section{Results and Discussion}

\section{Purification and N-Deglycosylation of Recombinant $\alpha$-Galactosidase}

A two-step column chromatography technique, including anion exchange and hydrophobic interaction, was used for the purification of extracellular recombinant $\alpha$-galactosidase from Aspergillus fumigatus 385708 expressed in $A$. sojae Ta1, under the control of the gpdA (glyceraldehyde3-phosphate dehydrogenase) promoter. In Figure 1, results of the purification steps are shown by SDS-PAGE.

The summary of the purification steps of the recombinant $\alpha$ galactosidase produced in A. sojae Tal was given in Table 1. Extracellular enzyme was purified 18.7 fold with an overall yield of $56 \%$ and the specific activity was $64.7 \mathrm{U} / \mathrm{mg}$ protein. In a previous study, native $\alpha$-galactosidase produced by Aspergillus fumigatus 385708 on locust bean gum, was purified by diethylamino ethyl (DEAE)- Sepharose and Phenyl Sepharose chromatography and the yield was $17.8 \%$ with 1596-fold purification (Puchart et al., 2000). This difference may be attributed to the fact that native $\alpha$-galactosidase was produced on complex medium containing locust bean gum (LBG). LBG as an inducer was required for $\alpha$ galactosidase production by $A$. fumigatus. In this study, recombinant $\alpha$-galactosidase was constitutively produced under the control of the gpdA promoter on glucose as the sole carbon source without the need of an inducer like LBG. As the simple medium was clearer and the purification was easier, lower degree of purification was enough and the yield was high. 


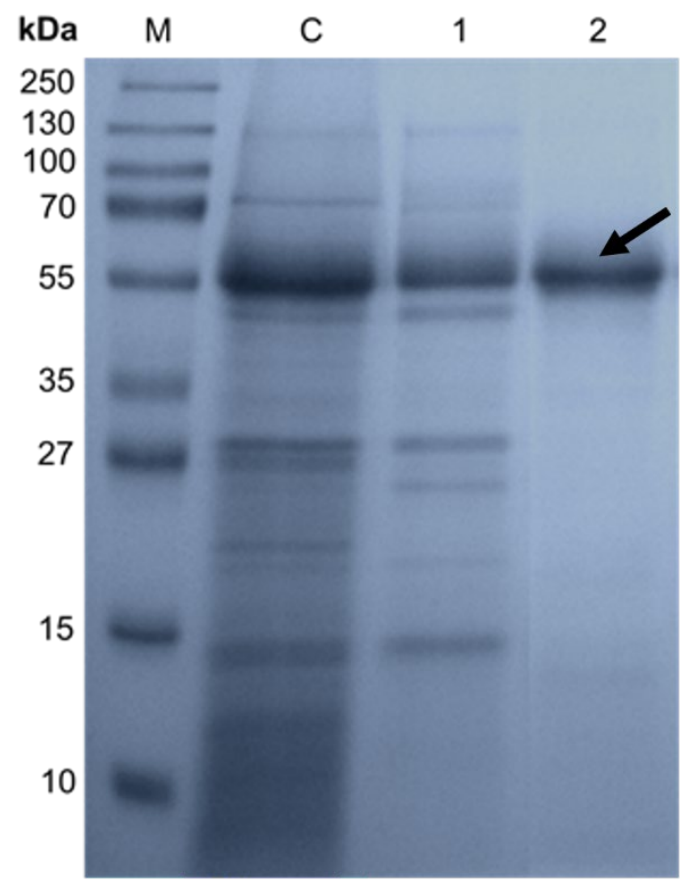

Figure 1.SDS-PAGE of the recombinant $\alpha$-galactosidase after staining with Coomassie Brilliant Blue G-250. Purification steps of recombinant $\alpha$-galactosidase; lane M: Marker protein ladder; lane C: Culture supernatant, lane 1: anion exchange chromatography, lane 2 : hydrophobic interaction chromatography.

Table 1. Summary of the purification of recombinant $\alpha$-galactosidase from $A$. sojae Ta1 by anion exchange chromatography (AEC) and hydrophobic interaction chromatography (HIC).

\begin{tabular}{ccccccccc}
\hline Steps & $\begin{array}{c}\text { Volume } \\
(\mathrm{mL})\end{array}$ & $\begin{array}{c}\text { Protein } \\
\text { Conc. } \\
(\mathrm{mg} / \mathrm{mL})\end{array}$ & $\begin{array}{c}\text { Total } \\
\text { Protein } \\
(\mathrm{mg})\end{array}$ & $\begin{array}{c}\text { Activity } \\
(\mathrm{U} / \mathrm{mL})\end{array}$ & $\begin{array}{c}1^{*} \text { Specific } \\
\text { Activity } \\
(\mathrm{U} / \mathrm{mg})\end{array}$ & $\begin{array}{c}\text { Total } \\
\text { Activity } \\
(\mathrm{U})\end{array}$ & $\begin{array}{c}2^{*} \text { Yield } \\
(\%)\end{array}$ & $\begin{array}{c}3^{*} \text { Purification } \\
(\text { Fold })\end{array}$ \\
\hline $\begin{array}{c}\text { Crude } \\
\text { Extract }\end{array}$ & 57 & 1.76 & 100.3 & 6.1 & 3.46 & 347 & 100 & 1 \\
$\begin{array}{c}\text { AEC } \\
\text { HIC }\end{array}$ & 30 & 0.14 & 4.2 & 6.8 & 48.6 & 204 & 58.8 & 14 \\
& 30 & 0.1 & 3 & 6.47 & 64.7 & 194 & 56 & 18.7
\end{tabular}

${ }^{1 *}$ Specific Activity $(\mathrm{U} / \mathrm{mg}): \alpha$-Gal activity $(\mathrm{U} / \mathrm{mL}) /$ Protein concentration $(\mathrm{mg} / \mathrm{mL})$

${ }^{2 *}$ Yield (\%): [Total $\alpha$-gal activity $(\mathrm{U} / \mathrm{mL}) /$ Crude total $\alpha$-gal activity $\left.(\mathrm{U} / \mathrm{mL})\right]$ x 100

${ }^{3 *}$ Purification (Fold): $\alpha$-Gal specific activity (U/mg) / Crude $\alpha$-gal specific activity (U/mg)

$\alpha$-Galactosidase from A. fumigatus (Acc. No. ACO72591) has a molecular mass of $49 \mathrm{kDa}$ with 4 potential N-glycosylation sites, based on the translated amino acid sequence data. The molecular mass of the native enzyme (Puchart et al., 2000), was reported as $57 \mathrm{kDa}$. Indeed, the recombinant enzyme also appeared as $57 \mathrm{kDa}$ on SDS-PAGE, however, after treatment with $\mathrm{N}$-glycanase, the molecular mass of the protein band was decreased to $c .50 \mathrm{kDa}$ (Figure 2.) supporting the presence of $\mathrm{N}$-glycosylation, and indicates that the recombinant $\alpha$-galactosidase produced in $A$. sojae Tal has undergone posttranslational processing similar to that of the native enzyme. 


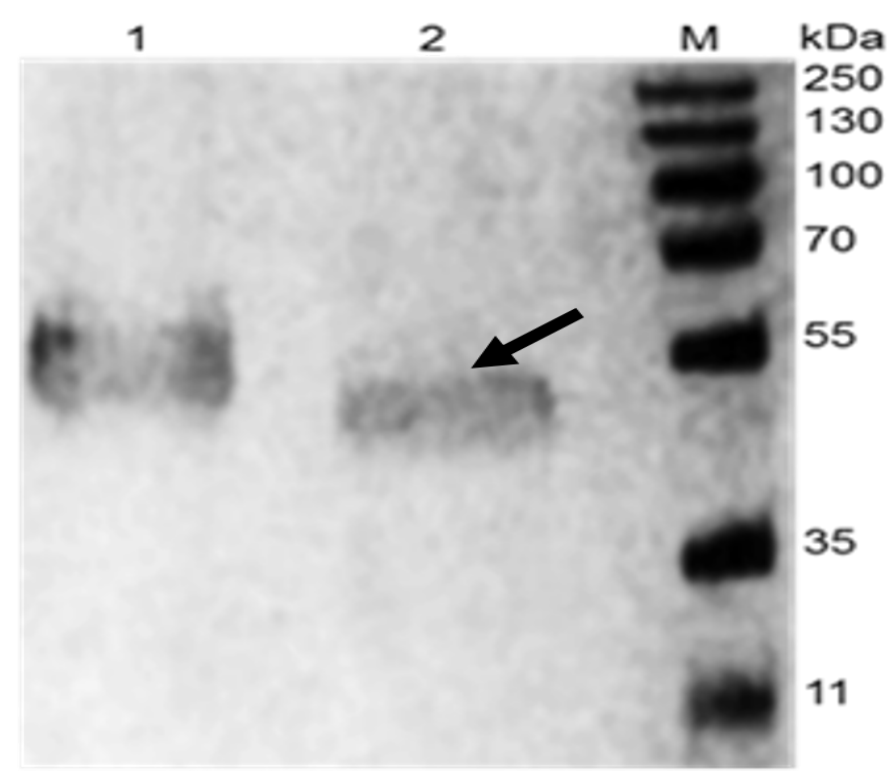

Kinetic Analysis of Recombinant $\alpha$-galactosidase

Figure 2. $\mathrm{N}$-deglycosylation of recombinant $\alpha$-galactosidase; lane 1: purified recombinant $\alpha$-galactosidase, lane 2: purified recombinant $\alpha$-galactosidase after $\mathrm{N}$-glycanase treatment.

Kinetic analysis of recombinant $\alpha$-galactosidase revealed that the enzyme obeys Michaelis-Menten kinetics. Simple Michaelis-Menten kinetics has been reported for several enzymes of Aspergilli (Zapater et. al., 1990, Neustroev et. al., $1991)$. The $V_{\max }$ and $K_{m}$ values of recombinant $\alpha$-galactosidase for the hydrolysis of $p$ NPGal were $78 \pm 2 \mathrm{U} / \mathrm{mg}$ protein and $0.45 \pm 0.04 \mathrm{mM}$, respectively. In the native enzyme the $\mathrm{V}_{\max }$ was found to be $52.4 \mathrm{U} / \mathrm{mg}$ protein and the $\mathrm{K}_{\mathrm{m}}$ was $0.5 \mathrm{mM}$ (Puchart et al., 2000). The differences between the native and the recombinant $\alpha$-galactosidase may result from the impurities coming from the different purification procedures.

\section{Effects of $p H$ and Temperature on Recombinant a-Galactosidase Activity and Stability}

The effect of $\mathrm{pH}$ on recombinant $\alpha$-galactosidase activity and stability were determined over a $\mathrm{pH}$ range of 2.5-8.0 under standard assay conditions. $\alpha$-Galactosidase was most active between $\mathrm{pH} 4-6$. The highest $\alpha$-galactosidase activity was observed at $\mathrm{pH}$ 4.5, as shown in Figure 3.a. This slightly acidic $\mathrm{pH}$ optimum is characteristic for fungal glycosyl hydrolases (Dey and Pridham, 1972).

Figure 3.b shows the retained $\alpha$-galactosidase activity after $2 \mathrm{~h}$ and $4 \mathrm{~h}$ incubations at different $\mathrm{pH}$ values. $\alpha$-Galactosidase was most active around $\mathrm{pH} 4.5$ and retained c. $60 \%$

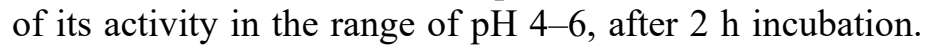

However, after $4 \mathrm{~h}$ incubation the retained activity was only within the range of $12-27 \%$.

The effect of temperature on recombinant $\alpha$-galactosidase activity and stability were determined over a temperature range of $20-80^{\circ} \mathrm{C}$, under standard assay conditions. $\alpha$-Galactosidase was most active at $50-60^{\circ} \mathrm{C}$, as shown in Figure 3.c.

Figure 3.d shows the retained $\alpha$-galactosidase activity after 1,3 , and $5 \mathrm{~h}$ incubations at different temperatures. More than $60 \%$ of activity was retained up to $50^{\circ} \mathrm{C}$ even after $5 \mathrm{~h}$ incubation. Above this temperature, recombinant $\alpha$-galactosidase rapidly lost its stability. Although recombinant $\alpha$-galactosidase was most active at $50-60^{\circ} \mathrm{C}$, it could preserve only $8 \%$ of its activity after $1 \mathrm{~h}$ incubation at $60^{\circ} \mathrm{C}$. On the other hand, the retained activities were around $75 \%$ even after $5 \mathrm{~h}$ incubation at lower temperatures, up to $40^{\circ} \mathrm{C}$.

The observed temperature optimum and temperature stability of the recombinant enzyme were similar to those reported for the native enzyme (Puchart et al., 2000), and were high in terms of thermostability, compared to other fungal $\alpha$-galactosidases (Kotwal et. al., 1998; Mi et. al., 2007). However, thermostability of the enzyme was lower than $\alpha$ galactosidases from the extremophilic bacteria Thermotoga neapolitana (Duffaud et al., 1997) and T. maritima (Liebl et al., 1998).

\section{Effects of Chemical Reagents on Recombinant $\alpha$-Galactosidase Activity}

The effects of metal ions and different protein denaturing agents on recombinant $\alpha$-galactosidase activity were analysed by measuring the residual activity after incubation of the enzyme with $1 \mathrm{mM}$ of different reagents for 90 minutes (Figure 4).

Recombinant $\alpha$-galactosidase activity was not significantly affected by $\mathrm{Ca}^{2+}, \mathrm{Sr}^{2+}, \mathrm{Zn}^{2+}, \mathrm{Cu}^{+2}, \mathrm{Co}^{2+}, \mathrm{Cd}^{2+}, \mathrm{Ba}^{2+}, \mathrm{Cr}^{3+}$, $\mathrm{B}^{3+}$, as well as the metal chelating agent, EDTA and the detergent, SDS. The fact that recombinant $\alpha$-galactosidase activity was not affected by EDTA, suggests that $\alpha$-galactosidase is not a metalloenzyme. $\mathrm{Ag}^{+1}$ and $\mathrm{Hg}^{2+}$ extremely inactivated $\alpha$-galactosidase activity with 16 and $18 \%$ residual activities, respectively. The inhibition of $\alpha$-galactosidases with $\mathrm{Ag}^{+1}$ and $\mathrm{Hg}^{2+}$ was reported previously (Zapater et al., 1990) and suggests reaction with thiol groups and/or carboxyl, amino and imidazolium group of histidine in the active site (Dey and Pridham, 1972). $\mathrm{Fe}^{2+}$ also highly inhibited the activity up to $36 \%$ residual activity. However, $\mathrm{Mg}^{+2}$, $\mathrm{Li}^{+1}, \mathrm{~Pb}^{+2}, \mathrm{Mn}^{+2}$, biotin and $\mathrm{I}^{+1}$ enhanced the activity of $\mathrm{r}-\alpha-$ galactosidase reaching up to $29 \%$ enhancement in the presence of $\mathrm{Mg}^{+2}$. Activation by $\mathrm{Mg}^{+2}$ and $\mathrm{Mn}^{+2}$ agreed with the 
results obtained for $\alpha$-galactosidase from Thermomyces lanuginosus (Rezessy-Szabó et al., 2007). The cysteine-inhibitor, $\beta$-mercaptoethanol and a reactive chemical element, $\mathrm{Al}^{+3}$ slightly inhibited $\alpha$-galactosidase activity ( $82 \%$ and $78 \%$, respectively).

\section{Transgalactosylation Activity of $\alpha$-Galactosidase}

The ability of recombinant $\alpha$-galactosidase to perform transfer reaction in addition to hydrolysis was studied. $\alpha$-Galactosidase from A. fumigatus previously shown to catalyse efficient transgalactosylation reaction with oligosaccharides, especially with $\beta$-1,4-manno-series acceptors, yielded low level of transfer ability to a variety of monosaccharide and disaccharides (Puchart and Biely, 2005). In this study, different monosaccharides and disaccharides were tested as acceptor in $\alpha$-galactosidase mediated transfer reactions and the results were analysed by TLC, ESI-MS, and HPLC.

In the presence of high acceptor concentrations $(1 \mathrm{M})$, purified recombinant $\alpha$-galactosidase $(0.5 \mathrm{U} / \mathrm{mL})$ catalysed the transfer of $\alpha-D$-galactosyl residues from $p$ NPGal $(0.25 \mathrm{M})$ on to monosaccharide (galactose, glucose, and mannose) and disaccharide (cellobiose, lactose, maltose, and sucrose) acceptors, as monitored by TLC (Figure 5). On the other hand, the monosaccharides, xylose, arabinose, fucose, which do not possess the 6-hydroxymethyl group, the ketose, fructose and the disaccharide, melibiose did not prove to be good acceptors for $\alpha$-galactosidase-mediated transgalactosylation.

Transgalactosylation reaction mixtures, obtained after an hour reaction at $50^{\circ} \mathrm{C}$, were also analysed more sensitively using electrospray ionization-time of flight mass spectrometry (ESI-TOF MS) in positive mode. The ESI-MS showed $\mathrm{m} / \mathrm{z}$ of $365,486,527$, and 648 corresponding to the calculated values of the $\mathrm{Na}^{+}$adduct of $\alpha$ - $D$-galactobiose $\left(\mathrm{Gal}_{2}\right)$, $p \mathrm{NP}-\alpha-D$-galactobioside $\quad\left(p \mathrm{NP} \alpha \mathrm{Gal}_{2}\right), \quad \alpha$ - $D$-galactotriose $\left(\mathrm{Gal}_{3}\right)$ and $p \mathrm{NP}-\alpha-D$-galactotrioside $\left(p \mathrm{NP} \alpha \mathrm{Gal}_{3}\right)$, respectively with the galactose $\left([\mathrm{M}+\mathrm{Na}]^{+}\right.$at $\left.m / z 203\right)$ as acceptor (Figure 6.a). The products except $\mathrm{Gal}_{2}$ was in trace amount that they could be detected only by ESI-MS but not by TLC and HPLC.

In the case of glucose acceptor $\left([\mathrm{M}+\mathrm{Na}]^{+}\right.$at $\left.\mathrm{m} / \mathrm{z} 203\right)$, only the $\mathrm{m} / \mathrm{z}$ of 365 corresponding to a calculated values of the $\mathrm{Na}^{+}$adduct of a disaccharide (GalGlc and $\mathrm{Gal}_{2}$ ) was observed by ESI-MS analysis (Figure 6.b). Unlike galactose and mannose acceptors, trisaccharide or $p$ NP-trisaccharide formations were not observed with glucose acceptor.
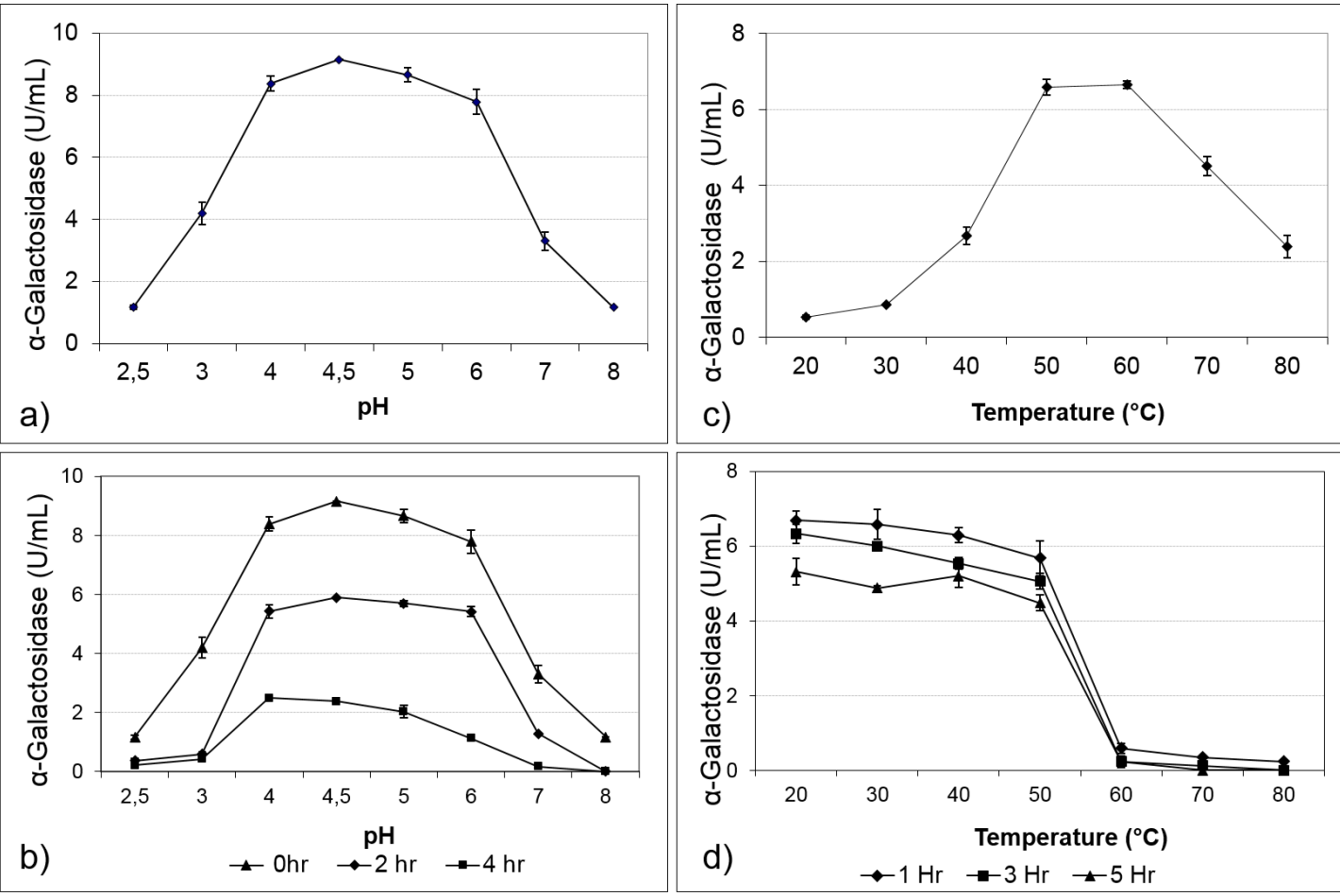

Figure 3. pH-dependence of recombinant $\alpha$-galactosidase activity (a) and stability (b); temperature dependence of $r-\alpha$-galactosidase activity (c) and stability (d). 


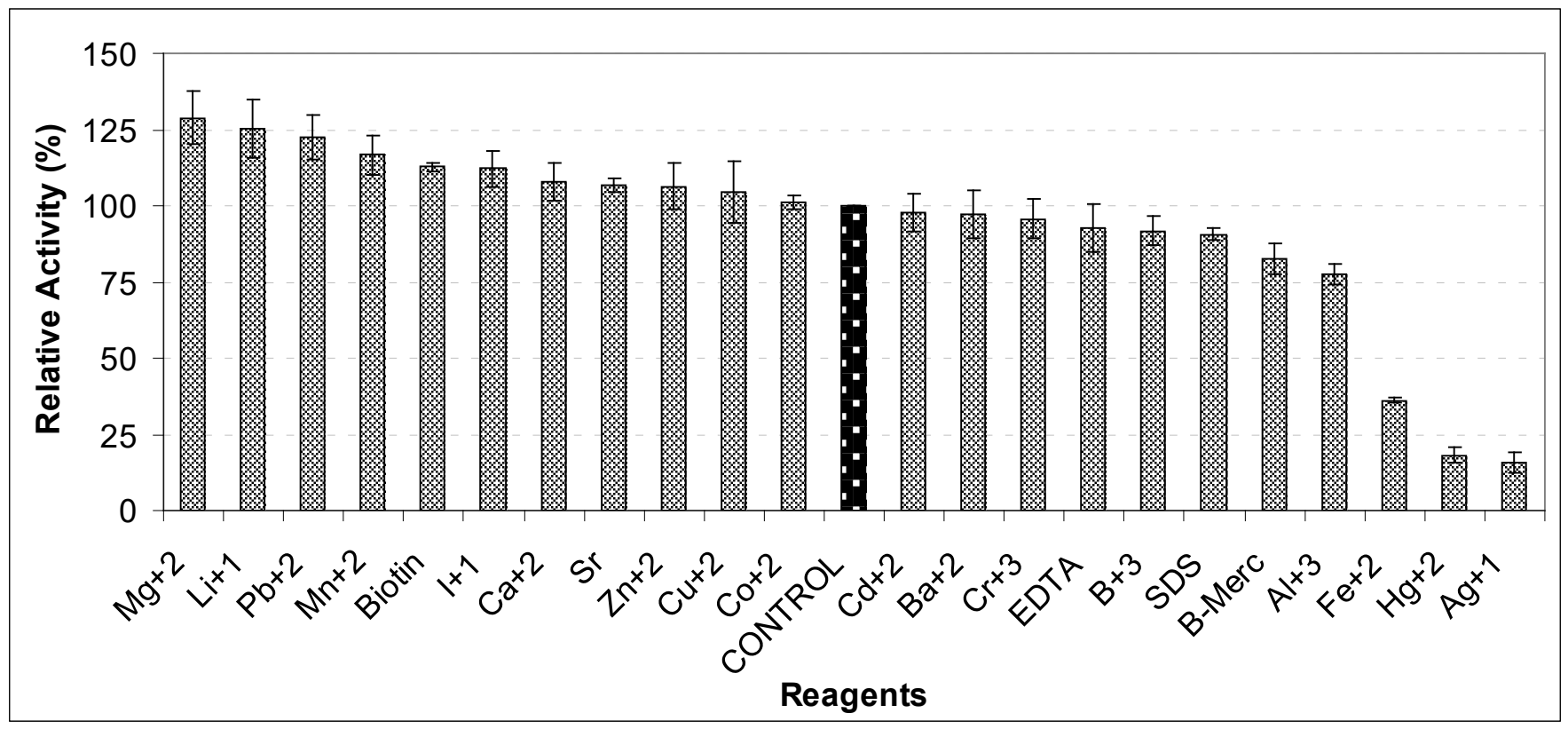

Figure 4. The effect of metal ions and chemical reagents on recombinant $\alpha$-galactosidase activity.

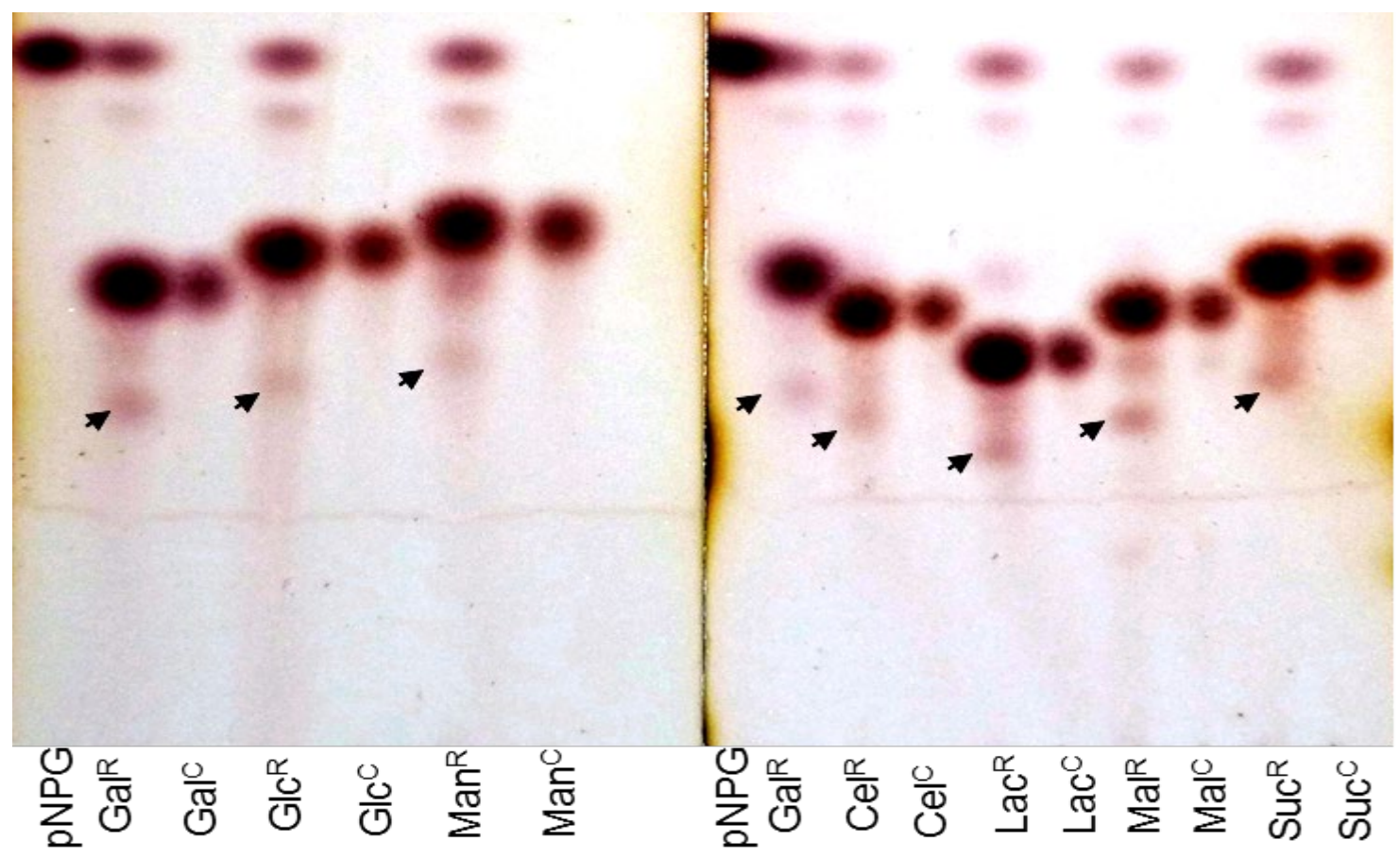

Figure 5. TLC analysis of transgalactosylation. R: Reaction mixture; C: control Sugar. 
In addition to $\alpha-D$-disaccharide (GalMan and $\mathrm{Gal}_{2}$ ) peak $(\mathrm{m} / z$ of 365$)$ and $p \mathrm{NP}-\alpha-D$-disaccharide peak $(\mathrm{m} / z$ of 486$)$, $\mathrm{m} / z$ of 648 corresponding to the calculated values of the $\mathrm{Na}^{+}$ adduct of $p$ NP- $\alpha-D$-trisaccharide, was also detected by ESIMS, when mannose was used as the acceptor (Figure 6.c). The formation of $\mathrm{Gal}_{2}$ in the reaction mixtures containing glucose and mannose as acceptor sugars also takes place by the autocondensation reaction of galactose units liberated from $p$ NPGal hydrolysis. These disaccharides could not be differentiated by ESI-MS due to the equal molecular weights of the disaccharides. On the other hand, the amounts of $\mathrm{Gal}_{2}$ were negligible as the $\mathrm{Gal}_{2}$ spots could not be detected by TLC analysis as shown in Figure $5\left(\mathrm{Glc}^{\mathrm{R}}\right.$ and $\mathrm{Man}^{\mathrm{R}}$ ). Excess amounts of acceptors, glucose and mannose, obviously changed the preference of the reaction towards glucose and mannose acceptors than the galactose.

After $1 \mathrm{~h}$ incubation with $\alpha$-galactosidase, trisaccharides were synthesized from cellobiose, lactose, maltose, and sucrose, by the addition of a galactose unit as shown by TLC analysis (Figure 5). ESI-MS analysis gave $\mathrm{m} / \mathrm{z}$ signals of 527 corresponding to the calculated molecular masses of the $\mathrm{Na}^{+}$ adduct of galactosyl-cellobiose, galactosyl-lactose, galactosyl-maltose, and galactosyl-sucrose (Figure $6 \mathrm{~d}, \mathrm{e}, \mathrm{f}, \mathrm{g}$ ).

ESI-MS analysis of reactions with xylose, arabinose, fucose, fructose, and melibiose acceptor did not give any positive signal corresponding to transgalactosylation products.

While the stereoselectivity on synthesis is rigid for either $\alpha$ or $\beta$ configuration in the anomeric centre, glycosidases generally lack the regioselectivity for the formation of glycosidic bond. Consequently, isolation of the desired regioisomer from the reaction mixtures is difficult. Two principal factors, the sources of the enzyme and the kinds of substrates used, affecting the regioselectivity of glycosidases have been reported previously (Homann and Seibel, 2009; Miyasato and Ajisaka, 2004; Usui et al., 1996).

As known from the previous NMR analyses of the transgalactosylated products carried out by Puchart and Biely (2005), $\alpha$-Galactosidase of A. fumigatus specifically forms $\alpha$-galactosidic linkage between galactosyl unit and the acceptor sugar and transgalactosylates the oligosaccharide acceptors at primary C-6 hydroxymethyl groups. In addition, autocondensation of $p \mathrm{NPGal}$ with galactosyl residue was found to take place predominantly at positions O-6 and O3.

Apart from being one of the most important groups of prebiotic oligosaccharides, galactooligosaccharides with $\alpha$-D-galactosidic linkages, especially the various positional isomers $(\alpha-1,2, \alpha-1,3, \alpha-1,4$, and $\alpha-1,6)$ of $\alpha$-galactobiose $\left(\alpha-\mathrm{Gal}_{2}\right)$, participate in various biological processes (Yamashita et al., 2005).

Quantitative analysis of $\alpha$-galactooligosaccharide formation with the donor $p$ NPGal, which has a good leaving group, was performed by HPLC and the results are given in Table 2 and Figure 7. Galactose, glucose, and mannose were found to be efficiently transgalactosylated among the monosaccharides. After 1-hour reaction, $46 \%$ of initial galactose, $33.4 \%$ of initial glucose and $26 \%$ initial mannose were galactosylated. In the reaction mixtures containing disaccharides as acceptor, $\mathrm{Gal}_{2}$ formation was preferred over trisaccharide formation and cellobiose, lactose, maltose, and sucrose were transgalactosylated with lower yields ranging between $1.2-4 \%$.

After 1-hour reaction at $50^{\circ} \mathrm{C}$, galactose (Figure 7.a) and glucose (Figure 7.b) acceptors were transgalactosylated by $\alpha$-galactosidase with $46 \%$ and $33.4 \%$ yields, respectively. As galactose and mannose had the same retention time on chromatogram (Figure 7.a and c), HPLC could not separate them. However, the yield of transgalactosylation reaction containing mannose acceptor was estimated to be lower than the yield of reaction with galactose acceptor (46\%) and higher than the yield of reaction with glucose acceptor (33.4\%) based on visual evaluation of TLC chromatograms (Figure 5). The trisaccharides detected by ESI-MS analysis of reaction mixtures with galactose (Figure 6.a) and mannose (Figure 6.c) acceptors were not detected and quantified by HPLC.

In the transgalactosylation reaction mixtures containing disaccharides as acceptor, $\mathrm{Gal}_{2}$ formation was preferred over the trisaccharide formation and cellobiose (Figure 7.d), lactose (Figure 7.e), maltose (Figure 7.f), and sucrose (Figure 7.g), were transgalactosylated with low yields, 1.2, 2.2, 4, and $2.5 \%$, respectively (Table 2 ). 


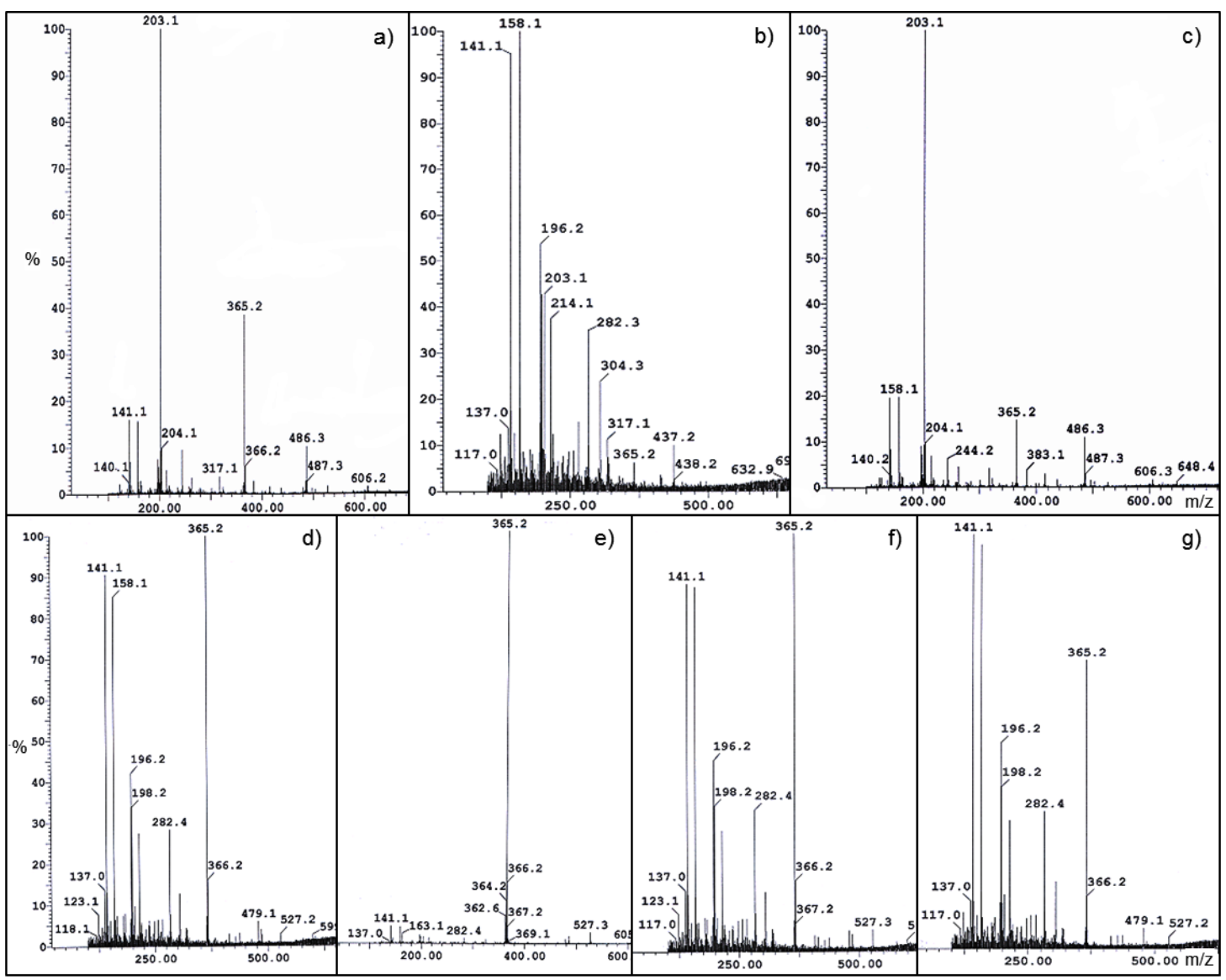

Figure 6. ESI-MS analysis of transgalactosylation mixtures containing different acceptors; a:Galactose; b:Glucose; c: mannose; d:cellobiose; e: lactose; f:maltose; e:sucrose.

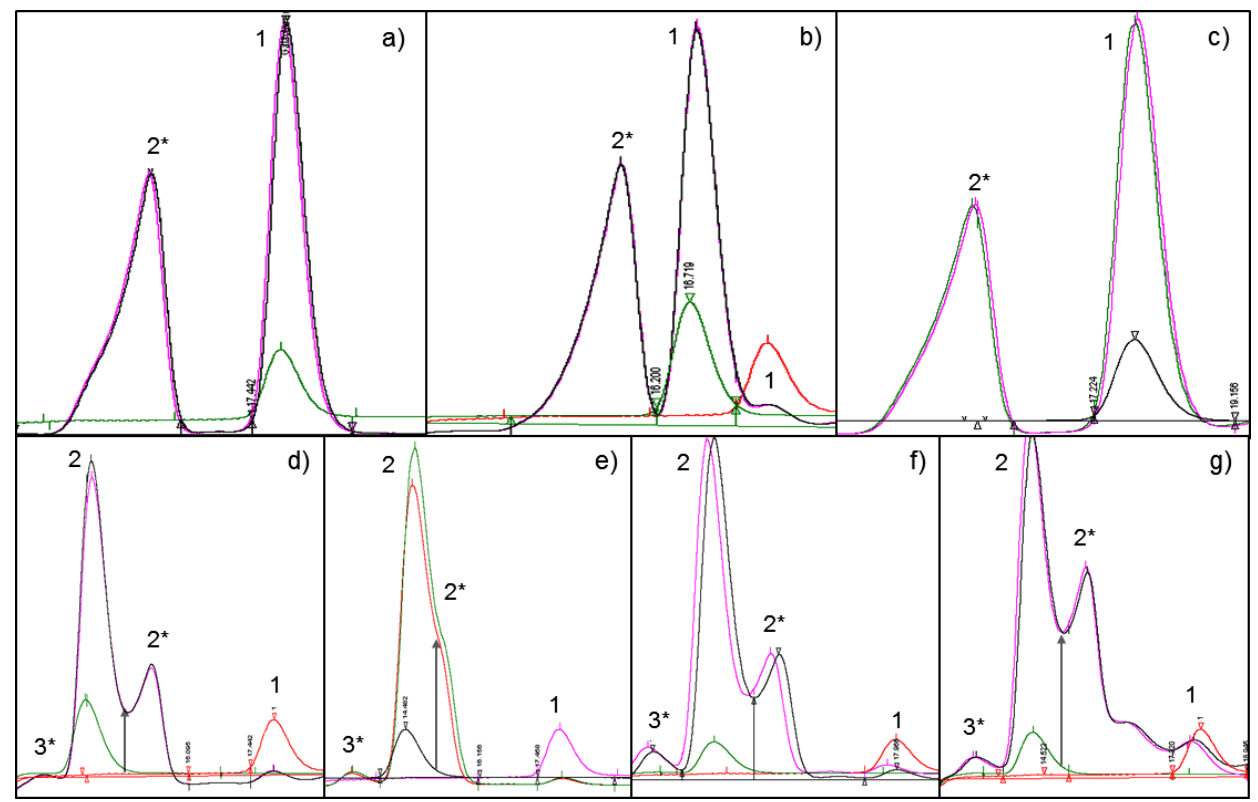

Figure 7. HPLC analysis of transgalactosylation mixtures containing different acceptors; a:Galactose; b:Glucose; c: mannose; d:cellobiose; e: lactose; f:maltose; e:sucrose. 1:monosaccharide; 2:disaccharide; 3 : trisaccharide (* used to specify reaction products). 
Table 2. Yields of transgalactosylation reactions analysed by the HPLC.

\begin{tabular}{lc}
\hline Acceptors & $\begin{array}{c}\text { Transgalactosylated } \\
\text { product (\%) }\end{array}$ \\
\hline \multicolumn{1}{c}{ Monosaccharides } \\
Arabinose & nd \\
Fructose & nd \\
Fucose & nd \\
Xylose & nd \\
Galactose & 46 \\
Glucose & 33.4 \\
Mannose & $33.4<x<46$ \\
& Disaccharides \\
Cellobiose & 1.2 \\
Lactose & 2.2 \\
Maltose & 4 \\
Melibiose & nd \\
Sucrose & 2.5 \\
\hline
\end{tabular}

nd: not detected.

Efficient transgalactosylation activity was obtained with higher oligosaccharide acceptor and transfer reaction to the internal units of oligosaccharide acceptors, which is unique among glycoside hydrolases, was achieved with the native $\alpha$-galactosidase enzyme. However, the observed yields in the present study are significantly higher than those obtained for the native enzyme. The yields with the same mono- and disaccharide acceptors were lower than $1 \%$ with the native enzyme. The only exception was with cellobiose acceptor, which resulted in an almost 3-fold higher yield with the native enzyme (Puchart and Biely, 2005). The reaction mixtures applied in this study was different from the previous study carried on by native enzyme. In this study, excess amount of acceptor sugars over the donor sugar was used whereas excess amount of donor sugar over the acceptor sugars was used with the native enzyme. As the yield was calculated by the ratio of transgalactosylated acceptors to the initial amount of acceptor and excess amounts of acceptors were used, the obtained yields are actually higher than the observed.

Despite their importance in biological processes, increasing demand, and potential applications, large-scale synthesis of oligosaccharides are unavailable. Unlike protein or oligonucleotide synthesis, oligosaccharide synthesis is challenging due to their complex structure and unavailable universal route for their synthesis. A number of methods have been developed to meet the needs. In order to improve the transgalactosylation yield, glycosynthases were introduced
(Mackenzie et al., 1998; Moracci et al., 1998). Glycosynthases are mutant glycosidases in which the active site nucleophilic residue is replaced with a non-nucleophile. These mutant glycosidases are able to synthesize the oligosaccharides more efficiently without hydrolysing the newly formed oligosaccharides. Although several glycosidases active on $\beta$-O-linked sugars have been converted to glycosynthases (Perugino et al., 2004; Honda and Kitaoka, 2006; Shaikh and Withers, 2008), few numbers of $\alpha$-glycosynthases, like $L$-fucosidase (Cobucci-Ponzano et al., 2009; Wada et al., 2008) are available. Recently, Cobucci-Ponzano et al., (2011) reported $\alpha$-glycosynthase derived from a prokaryotic $\alpha$-galactosidase from Thermotoga maritime. They achieved $33 \%$ yield in $\alpha$-Gal-(1-6)- $\alpha$-Glc-4NP synthesis with 4 NP- $\alpha-$ Glc acceptor, $40 \%$ yield in $\alpha$-Gal-(1-2)- $\alpha$-Xyl-4NP synthesis with 4NP- $\alpha$-Xyl and 38\% yield in $\alpha$-Gal-(1-4)- $\alpha$-Xyl4NP synthesis with 4NP- $\beta$-Xyl and $51 \%$ yield in $\alpha-G a l-\alpha-$ Man-4NP synthesis with 4NP- $\alpha$-Man acceptor. As in the synthesis of oligosaccharides up to $46 \%$ yield with monosaccharide acceptor (Gal) by recombinant $\alpha$-galactosidase and up to $38.5 \%$ yield with oligosaccharide acceptor (Man4) by native $\alpha$-galactosidase from $A$. fumigatus could be achieved without any mutation, it is worth putting forward $\alpha$-galactosidase from A. fumigatus as a promising and low cost biocatalysts for the synthesis of galactooligosaccharides.

\section{Conclusions}

$\alpha$-Galactosidase of A. fumigatus IMI 385708 having unique transgalactosylation activities was produced heterologously in $A$. sojae Ta1. The recombinant enzyme was more efficiently purified by a two-step anion-exchange and hydrophobic interaction chromatography method by means of the gpdA promoter, allowing the use of glucose as the carbon source instead of LBG and resulting in higher production. The heterologous enzyme was similar to the native enzyme in terms of thermostability, $\mathrm{pH}$ stability and $\mathrm{N}$-glycosylation. Recombinant $\alpha$-galactosidase from A. fumigatus IMI 385708 efficiently transferred galactosyl residues to glucose, galactose, mannose, maltose, lactose, and sucrose using pNPGal and proved to be a promising tool for the synthesis of new galactooligosaccharides which can find new usages as prebiotics easily.

\section{Compliance with Ethical Standard}

Conflict of interests: The authors declare that for this article they have no actual, potential or perceived conflict of interests.

Acknowledgment: We acknowledge the help of Prof. Dr. Ufuk Bakır, (Department of Chemical Engineering, METU, Ankara, Turkey) for technical support for ÄKTA Prime FPLC system and Prof. Dr. Sabine Flitsch (Manchester Institute of Biotechnology, 
The University of Manchester, Manchester, UK) for ESI-TOF MS technical support.

Financial disclosure: This work was supported by grants from State Planning Agency of Turkey and Middle East Technical University, Project ID: 2087231.

\section{References}

Cobucci-Ponzano, B., Conte, F., Bedini, E., Corsaro, M.M., Parrilli, M., Sulzenbacher, G., Lipski, A., Dal Piaz, F., Lepore, L., Rossi, M. (2009). $\beta$-Glycosyl azides as substrates for $\alpha$-glycosynthases: Preparation of efficient $\alpha$ L-fucosynthases. Chemistry \& Biology, 16, 1097-1108.

Cobucci-Ponzano, B., Zorzetti, C., Strazzulli, A., Carillo, S., Bedini, E., Corsaro, M.M., Comfort, D.A., Kelly, R.M., Rossi, M., Moracci, M. (2011). A novel alpha-D-galactosynthase from Thermotoga maritima converts beta-Dgalactopyranosyl azide to alpha-galacto-oligosaccharides. Glycobiology, 21, 448-456.

Crout, D.H.G., Vic, G. (1998). Glycosidases and glycosyl transferases in glycoside and oligosaccharide synthesis. Current Opinion in Chemical Biology, 2, 96-111.

Dey, P.M., Pridham, J.B. (1972). Biochemistry of $\alpha$-galactosidases. Advanced Enzymology, 36, 91-130.

Dey, P.M., Patel, S., Brownleader, M.D. (1993). Induction of alpha-galactosidase in Penicillium ochrochloron by guar (Cyamopsis tetragonobola) gum. Biotechnology and Applied Biochemistry, 17, 361-371.

Duffaud, G.D., McCutchen, C.M., Leduc, P., Parker, K.N., Kelly, R.M. (1997). Purification and characterization of extremely thermostable beta-mannanase, beta-mannosidase, and alpha-galactosidase from the hyperthermophilic eubacterium Thermotoga neapolitana 5068. Applied and Environmental Microbiology, 63, 169-177.

Gibson, G.R., Roberfroid, M.B. (1995). Dietary Modulation of the human colonic microbiota: introducing the concept of prebiotics. Journal of Nutrition, 125, 1401-1412.

Gupta, R., Jung, E., Brunak, S. (2004). Prediction of N-glycosylation sites in human proteins. http://www.cbs.dtu.dk/services/NetNGlyc/

Gurkok, S., Soyler, B., Biely, P., Ogel, Z.B. (2010). Cloning and heterologous expression of the extracellular alphagalactosidase from Aspergillus fumigatus in Aspergillus sojae under the control of gpdA promoter. Journal of Molecular Catalysis B: Enzymatic, 64, 146-149.

Gurkok, S., Cekmecelioglu, D., Ogel, Z.B. (2011). Optimization of culture conditions for Aspergillus sojae expressing an Aspergillus fumigatus $\alpha$-galactosidase. Bioresource Technology, 102, 4925-4929.

Hashimoto, H., Katayama, C., Goto, M., Okinaga, T., Kitahata, S. (1995). Transgalactosylation catalyzed by $\alpha$-galactosidase from Candida guilliermondii $\mathrm{H}-404$. Bioscience, Biotechnology, and Biochemistry, 59(4), 619-623.

Hinz, S.W.A., Doeswijk-Voragen, C.H.L., Schipperus, R., Broek, L.A.M., Vincken, J.P., Voragen, A.G.J. (2005). Increasing the transglycosylation activity of $\alpha$-galactosidase from Bifidobacterium adolescentis DSM 20083 by site-directed mutagenesis. Biotechnology and Bioengineering, 93(1), 122-131.

Homann, A., Seibel, J. (2009). Towards tailor-made oligosaccharides-chemo-enzymatic approaches by enzyme and substrate engineering. Applied Microbiology and Biotechnology. 83, 209-216.

Honda, Y., Kitaoka, M. (2006). The first glycosynthase derived from an inverting glycoside hydrolase. Journal of Biological Chemistry, 281, 1426-1431.

Katrolia, P., Rajashekhara, E., Yan, Q., Jiang, Z. (2014). Biotechnological potential of microbial $\alpha$-galactosidases. Critical Reviews in Biotechnology, 34, 307-317.

Kotwal, S.M., Gote, M.M., Sainkar, S.R., Khan, M.I. \& Khire, J.M. (1998). Production of $\alpha$-galactosidase by thermophilic fungus Humicola sp. in solid-state fermentation and its application in soyamilk hydrolysis, Process Biochemistry, 33, 337-343.

Kurt, F., 2011. Biotransformations in Organic Chemistry: A Textbook, $6^{\text {th }}$ Eddition, Springer, Berlin. ISBN 978-3642-17393-6

Laemmli, U.K. (1970). Cleavage of structural proteins during the assembly of the head of bacteriophage T4. $\mathrm{Na}$ ture, 227, 680-685.

Liebl, W., Wagner, B., Schellhase, J. (1998). Properties of an a-galactosidase, and structure of its gene, galA, within 
an a- and B-galactoside utilization gene cluster of the hyperthermophilic bacterium Thermotoga maritima. Systematic and Applied Microbiology, 21, 1-11.

Lowry, O.H., Rosebrough, N.J., Farr, A.L., Randall, R.J. (1951). Protein measurement with the Folin phenol reagent. Journal of Biological Chemistry, 193, 265-275.

Mackenzie, L.F., Wan, Q.P., Warren, R.A.J., Withers, S.G. (1998). Glycosynthases: Mutant glycosidases for oligosaccharide synthesis. Journal of the American Chemical Society, 120, 5583-5584.

Mi, S., Meng, K., Wang, Y., Bai, Y., Yuan, T., Luo, H., Yao, B. (2007). Molecular cloning and characterization of a novel $\alpha$-galactosidase gene from Penicillium sp. F63 CGMCC 1669 and expression in Pichia pastoris. Enzyme and Microbial Technology, 40, 1373-1380.

Miyasato, M., Ajisaka, K. (2004). Regioreselectivity in beta-galactosidase-catalyzed transglycosylation for the enzymatic assembly of D-galactosyl-D- mannose. Bioscience, Biotechnology, and Biochemistry, 68, 20862090.

Moracci, M., Trincone, A., Perugino, G., Ciaramella, M., Rossi, M. (1998). Restoration of the activity of activesite mutants of the hyperthermophilic beta-glycosidase from Sulfolobus solfataricus: dependence of the mechanism on the action of external nucleophiles. Biochemistry, 37, 17262-17270.

Neustroev, K.N., Krylov, A.S., Abroskina, O.N., Firsov, L.M., Nasonov, V.V., Khorlin, A.Y., (1991). Isolation and properties of $\alpha$-galactosidase from Aspergillus awamori. Biochemistry USSR, 56, 288-296.

Perugino, G., Trincone, A., Rossi, M., Moracci, M. (2004). Oligosaccharide synthesis by glycosynthases. Trends in Biotechnology, 22, 31-37.

Puchart, V., Vrsanska, M., Bhat, M.K., Biely, P. (2000). Purification and characterization of $\alpha$-galactosidase from a thermophilic fungus Thermomyces lanuginosus. Biochimica et Biophysica Acta, 1524, 27-37.

Puchart, V., Biely, P. (2005). Glycosylation of internal sugar residues of oligosaccharides catalyzed by $\alpha$-galactosidase from Aspergillus fumigatus. Biochimica et Biophysica Acta, 1726, 206-216.
Rezessy-Szabó, J.M., Nguyen, Q.D., Hoschke, A., Braet, C., Hajós, G., Claeyssens, M. (2007). A novel thermostable $\alpha$-galactosidase from the thermophilic fungus Thermomyces lanuginosus CBS 395.62/b: Purification and characterization. Biochimica et Biophysica Acta, 1770, 5562.

Shaikh, F.A., Withers, S.G., (2008). Teaching old enzymes new tricks: Engineering and evolution of glycosidases and glycosyl transferases for improved glycoside synthesis. Biochemistry and Cell Biology, 86, 169-177.

Usui, T., Morimoto, S., Hayakawa, Y., Kawaguchi, M., Murata, T., Matahira, Y. (1996). Regioselectivity of beta-Dgalactosyl-disaccharide formation using the beta-D-galactosidase from Bacillus circulans. Carbohydrate Research, 285, 29-39.

Van Laere, K.M.J., Hartemink, R., Beldman, G., Pitson, S., Dijkema, C., Schols, H.A., Voragen A.G.J. (1999). Hydrolase and transglycosidase activity of Bifidobacterium adolescentis DSM $20083 \alpha$-galactosidase. Applied Microbiology and Biotechnology, 52(5), 681-688.

Wada, J., Honda, Y., Nagae, M., Kato, R., Wakatsuki, S., Katayama, T., Taniguchi, H., Kumagai, H., Kitaoka, M., Yamamoto, K. (2008). 1,2-alpha-l-Fucosynthase: a glycosynthase derived from an inverting alpha-glycosidase with an unusual reaction mechanism. FEBS Letters, 582(27), 3739-3743.

Wang, H., Ma, R., Shi, P., Xue, X., Luo, H., Huang, H., Bai, Y., Yang, P., Yao, B. (2014). A new $\alpha$-galactosidase from thermoacidophilic Alicyclobacillus sp. A4 with wide acceptor specificity for transglycosylation. Applied Biochemistry and Biotechnology, 174, 328-338.

Yamashita, A., Hashimoto, H., Fujita, K., Okada, M., Mori, S., Kitahata S. (2005). Reverse reaction of Aspergillus niger APC-9319 $\alpha$-galactosidase in a supersaturated substrate solution: production of $\alpha$-linked galactooligosaccharide ( $\alpha-\mathrm{GOS})$. Bioscience, Biotechnology, and Biochemistry, 69(7), 1381-1388.

Zapater, I.G., Ullah, A.H.J., Wodzinsky, R.J. (1990). Extracellular alpha-galactosidase (E.C. 3.2.1.22) from Aspergillus ficuum NRRL 3135 purification and characterization. Preparative Biochemistry, 20, 263-296. 